HISTORICAL AND CONTEMPORARY ARCHAEOLOGY AT AMAZON RAINFOREST:

TOWARDS AN ELASTIC ARCHAEOLOGY

Tiago Silva Alves Muniz

Como citar este artigo:

MUNIZ, Tiago Silva Alves. Arqueologia Histórica e Contemporânea na Amazônia: por uma arqueologia elástica. Cadernos do

Lepaarq, v. XVII, n.34, p. 272-289, Jul-Dez. 2020. 


\section{Arqueologia Histórica e Contemporânea na Amazônia: por uma arqueologia elástica}

Tiago Silva Alves Muniz

\begin{abstract}
Resumo:
O presente artigo visa abordar aspectos da arqueologia histórica e contemporânea na Amazônia abordando a "Arqueologia do Período da Borracha" como ponto de partida para construção de uma noção de modernidade. A partir da criação de materiais como luvas, botas de borracha para neve e, finalmente, com o advento dos pneumáticos, a borracha propiciou aos humanos esticar suas interações com o meio. À medida que tais interações foram expandidas com a invenção e consolidação do ocidentalismo (ou modernidade), os actantes e conhecimentos emaranhados foram separados, produzindo os discursos da cientificidade e conhecimento em oposição aos saberes locais, enredando complexa trama de significados, devires e agências. Através de uma abordagem plural e multiespecífica, pretendo situar o estudo da materialidade do período da borracha como um campo de estudo da arqueologia do capitalismo, da arqueologia da modernidade e ecologia histórica em aproximação à arqueologia pública e contemporânea de modo mais elástico, mirado para as materialidades e comunidades.
\end{abstract}

\section{Palavras-chave:}

teoria e método em arqueologia, arqueologia amazônica, arqueologia do capitalismo, ecologia histórica, patrimônios futuros.

\begin{abstract}
:
This article aims to address particular aspects of historical and contemporary archaeology at Amazon Rainforest, addressing the "Archaeology of Rubber Boom" as starting point for building up a notion of modernity. From the creation of materials such as gloves, rubber snow boots and, finally, with the advent of tires, rubber allowed humans to stretch their interactions with the environment. As these interactions were expanded with the invention and consolidation of Westernism (or modernity), the actants and entangled knowledge were separated, producing discourses of scientificity and knowledge in opposition to local knowledge, entangling a complex web of meanings, becomings and agencies. Through a plural and multispecific approach, I intend to situate the study of the materiality of rubber boom as a field of study on archaeology of capitalism, archaeology of modernity and historical ecology within more elastic approaches to public and contemporary archaeology, aimed at materialities and communities.
\end{abstract}

\section{Keywords:}

theory and method in archaeology, amazonian archaeology, archaeology of capitalism, historical ecology, heritage futures.

\footnotetext{
${ }^{a}$ Pesquisador visitante no Departamento de Ciências Culturais, Linnaeus University. Doutorando em Antropologia (Arqueologia), Universidade Federal do Pará. E-mail: tiago.samuniz@gmail.com
} 


\section{INTRODUÇÃO À ARQUEOLOGIA DO PERÍODO DA BORRACHA}

A Arqueologia na Amazônia possui maior foco de estudos em seu componente pré-colonial, sendo pesquisada há cerca de 200 anos (COSTA, 2017, GOMES, 2020). Entretanto, os estudos em arqueologia histórica na Amazônia se iniciam efetivamente apenas na década de 1980, com destaque para pesquisas desenvolvidas nos contextos militar, religioso, urbano e rural (COSTA, 2017). Mais recentemente, a extroversão de materiais arqueológicos (pré-coloniais e coloniais) encontrados em comunidades na Amazônia tem sido objeto de pesquisas em arqueologia pública e educação patrimonial junto às comunidades que habitam nas imediações de tais sítios arqueológicos (BEZERRA, 2011, 2012)

Cabe destacar que há uma crescente interdisciplinaridade entre estudos ecológicos e etnobotânicos que analisam a dinâmica da floresta amazônica relacionando-a com os sítios arqueológicos, estimulando a reflexão sobre as domesticações e modificações antrópicas que tiveram espaço em tais paleoambientes e hoje são percebidas como um produto das interações humanas e não-humanas em tal contexto (LEVIS et al., 2018). Desse modo, o manejo florestal e suas técnicas variadas ao longo tempo tem sido utilizadas para reconstruções paleoambientais, onde, o evento histórico mais estudado na Amazônia, e que também modificou a fitofisionomia do bioma amazônico se destaca: o período da borracha (MAEZUMI et al., 2018). Desse modo, a Hevea brasiliensis, a seringueira, foi a responsável por uma série de modificações em âmbito local, regional e global (e vice-versa, como veremos a seguir).

A fim de expandir os estudos dos múltiplos processos relacionados aos colonialismos botânicos, compreender que o colonialismo/imperialismo não está apenas interessado com a conquista do espaço ou território, mas também com a conquista do tempo, assumindo dessa maneira muitas formas, como o cancelamento ou subalternização de histórias locais (SHEPHERD, 2016). Destaca-se aqui o protagonismo do Jardim Botânico Real de Londres, Kew Gardens, e seu papel para a expansão colonial/imperial, onde o melhor exemplo é o caso das sementes de $H$. brasiliensis (BROCKWAY, 1982). Nesse sentido, faz-se necessária a expansão dos estudos acerca das diferentes frentes de colonialismo botânico dirigidas por parte do Império Britânico, o qual já se dispunha à pesquisa de uma série de espécies lactescentes pelo mundo, e encontrou na $H$. brasiliensis a espécie mais economicamente viável.

A busca por áreas de seringueiras nativas para a aquisição de sementes de borracha foi intensa na Amazônia, onde algumas localidades, como a vila de Boim (Reserva Extrativista TapajósArapiuns, Santarém, Pará) já se destacava por seu comércio regional (COHEN, 1985). Com o passar do tempo e início do boom da borracha, as seringueiras passaram a ser cultivadas também. Isso posto, não somente a heveicultura aumentou exponencialmente, mas principalmente depois da Grande Seca de 1877 no nordeste brasileiro, como também migrações dentro do Brasil começaram a ocorrer para explorar a seringa, conhecida na época como outro-negro (DAOU, 2004).

Estamos diante de dois fenômenos que por si transformaram a região norte do Brasil através do aumento populacional para o trabalho, à medida que os seringais também iam crescendo. 
Entretanto, com o crescimento do mercado asiático oriundo de sementes de borracha levadas do Baixo Amazonas para as colônias britânicas, a economia gomífera brasileira entra em decadência na virada do século XX, atingindo seu colapso definitivo na segunda década (MUNIZ, 2019, WEINSTEIN, 1993). Destarte, este trabalho chama atenção dos olhares dos arqueólogos históricos e contemporâneos para/por uma arqueologia do período da borracha, contendo diferentes dimensões de estudo, desde a sua ecologia histórica, migrações internas, antropologia da técnica, patrimônio material/imaterial, patrimônio tóxico, colonialidade/seringalidade e emaranhamentos envolvidos.

\section{A RELAÇÃO DE DUPLA TROCA NO PERÍODO DA BORRACHA: DO LOCAL AO GLOBAL E VICE-VERSA}

Sir Henry Allexander Wickham, em 1876, levou setenta mil sementes de borracha do Brasil para a Inglaterra e, por conseguinte, heveiculturas foram instaladas nas colônias britânicas na Ásia (JACKSON, 2011). Wickham (1873) em correspondências com o diretor de Kew Gardens à época, Joseph Dalton Hooker, manifesta o potencial da borracha de hevea a ser explorado e exemplifica os métodos de sangria de látex praticados, oferecendo também seus serviços de coleta para o Jardim Botânico Real de Londres (Figura 1).

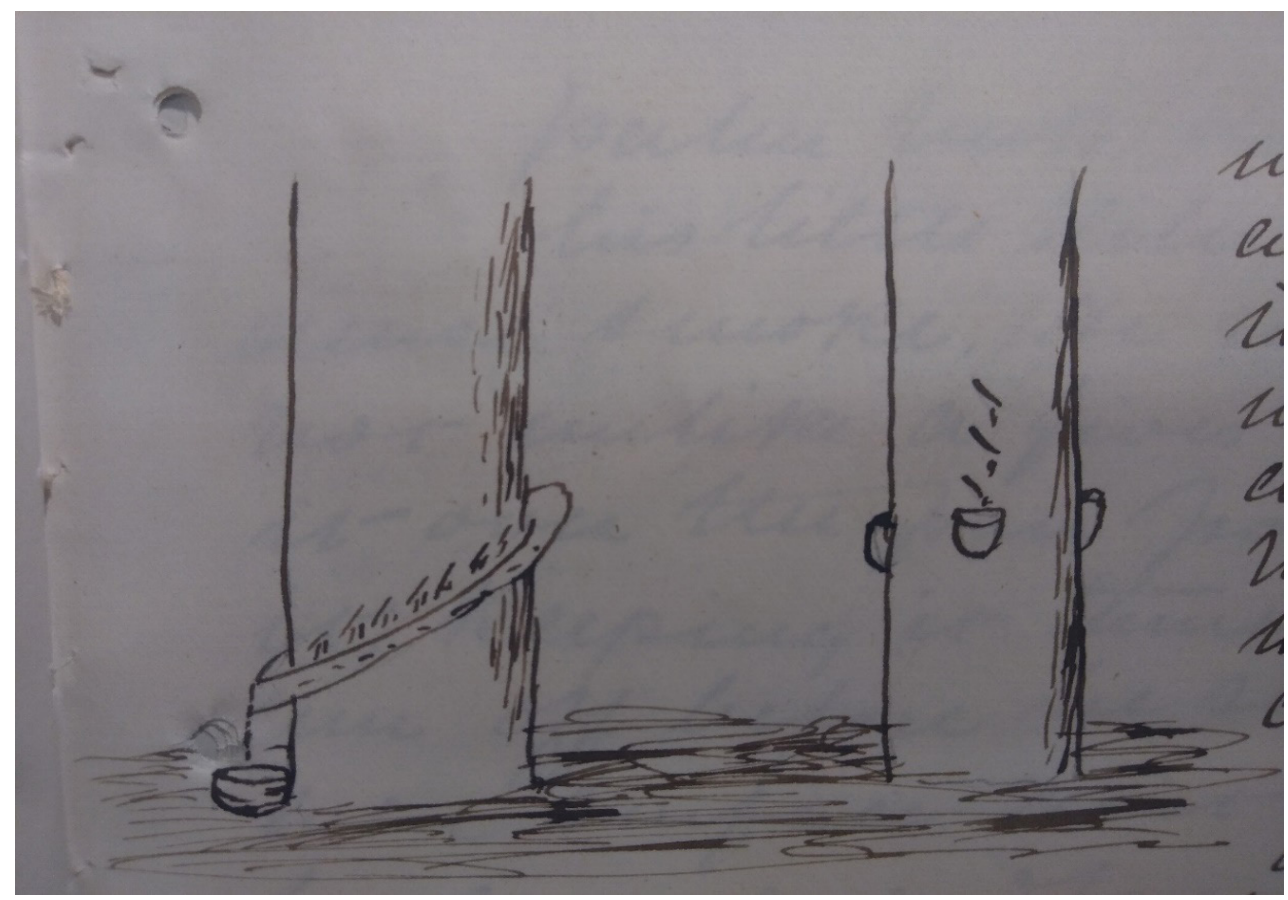

Figura 1: Esquema de extração de látex seguindo dois modelos: esquerda) uso de braceamento de caraná e argila; direita) uso de treps com ouriços de castanha. Fonte: (WICKHAM, 1873).

James Wells Champney, artista e ilustrador estadunidense, viajou pelo Brasil acompanhando o naturalista Herbert Huntington Smith e retratou cenas cotidianas da Amazônia oitocentista. Entre as ilustrações de Champney, destacam-se aqui duas nas quais configuram a presença da borracha em Santarém e seu modo de extração local em meados do século XIX (Figuras 2-3). 


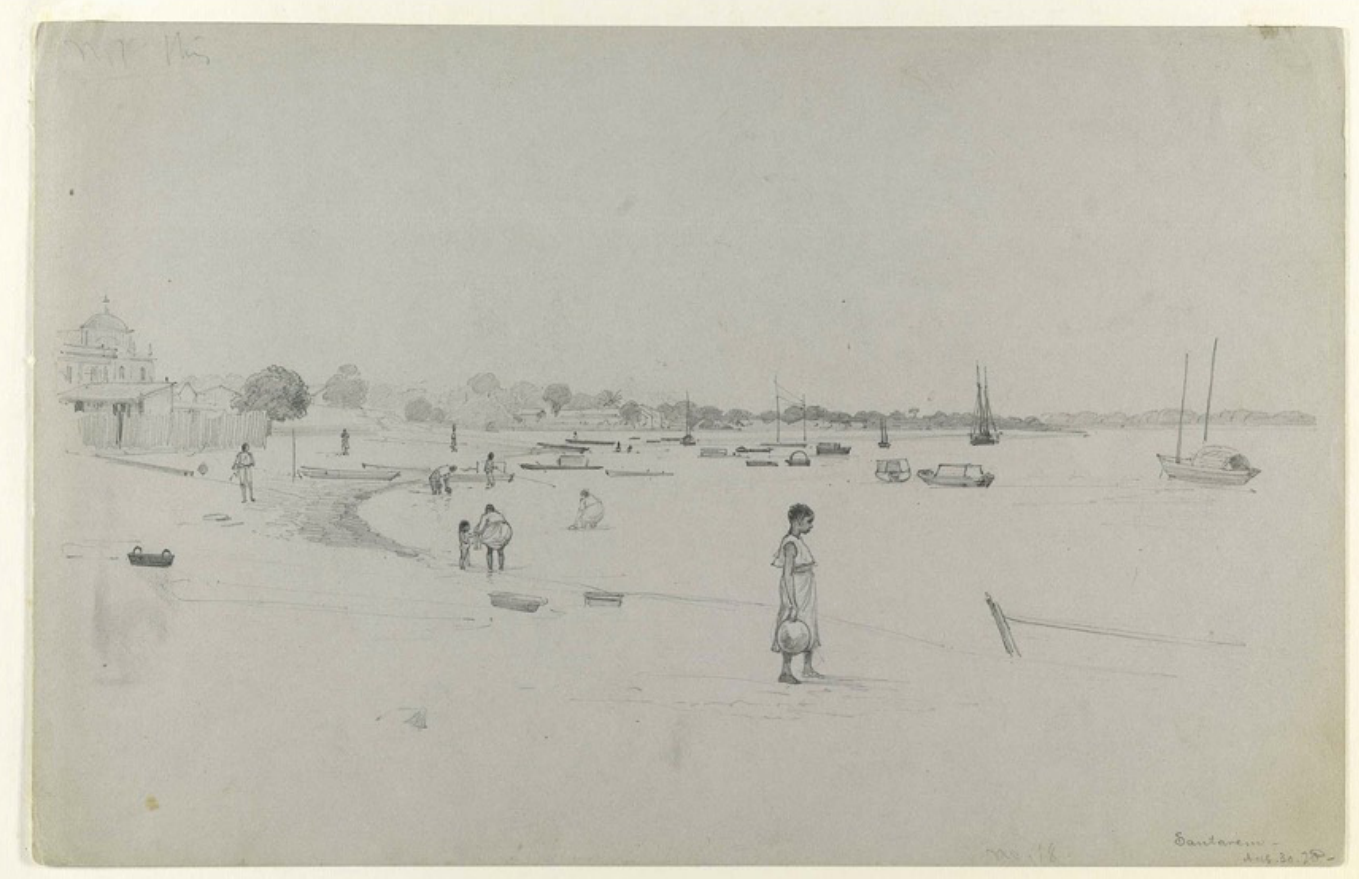

Figura 2: "Making rubber" e cenas cotidianas na orla de Santarém, Pará. (CHAMPNEY, 1860). Destaque circundando bolota de borracha.

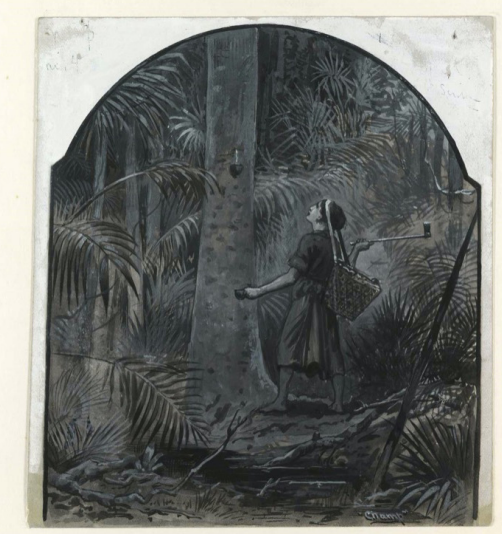

Figura 3: Extração de látex com golpe de machado e uso de ouriços de castanha-do-pará e jamanxim para coleta (CHAMPNEY, 1860).

Tal como a elaboração de técnicas e diferentes tipos de materiais associados à extração da borracha para aumentar a eficiência da produção gomífera, exposições anuais eram realizadas durante congressos sobre a borracha. Modelos de facas (Figura 4) e guias de boas práticas no cultivo e coleta estimulavam o desenvolvimento de pesquisas e fomento da indústria para manter as seringueiras cada vez mais saudáveis e produtivas. Acompanhando as novas tecnologias, novas técnicas também eram desenvolvidas e, aos poucos, tais novidades passam a ser introduzidas nos seringais amazônicos onde o uso de facas gradualmente substitui os machados, conforme 
representado em relatos históricos (Figura 5).

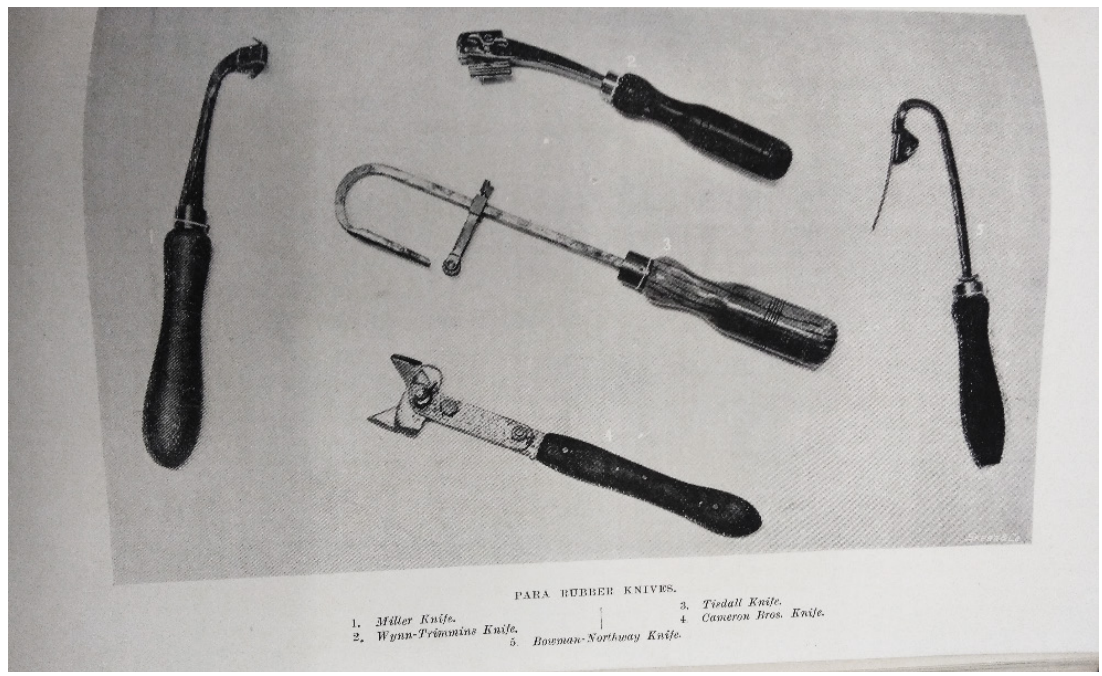

Figura 4: Diferentes designs de facas elaboradas para extração de látex, Congresso da Borracha de 1906 (WILLIS, 1906).

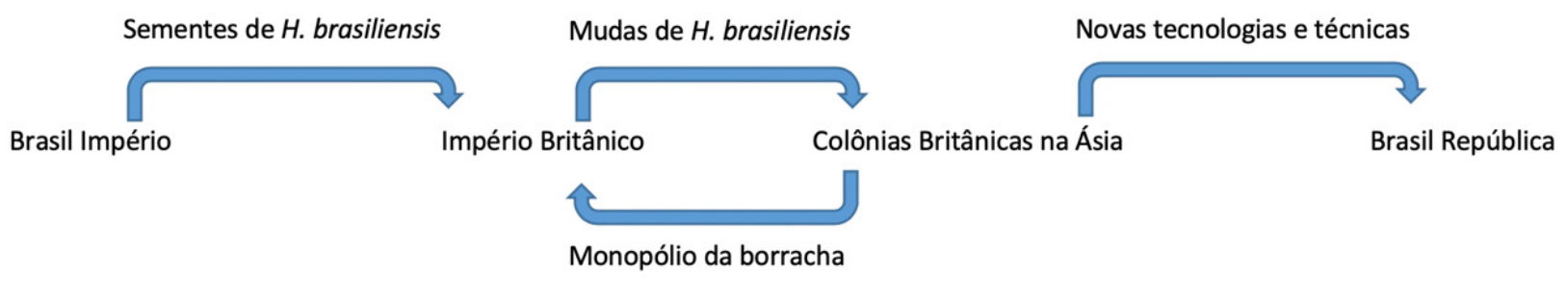

Figura 5: Esquema da colonialidade da borracha e mudanças causadas pela ascensão da produção da borracha em colônias britânicas na Ásia. Fonte: Autor.

Desse modo, uma série de materiais e conhecimentos associados foram desenvolvidos para a produção de borracha. Entretanto, a incorporação de novas técnicas e tecnologias transcorreu no sentido global-local e o corte "rabo-de-peixe" se consolidou como método mais utilizado na Amazônia (Fig. 6). Assim sendo, a paisagem da Amazônia passou a ser transformada, não somente com seringais cultivados para atender a demanda internacional, ou por um súbito aumento em seu povoamento, mas também em seus modos de fazer borracha com a chegada de novas técnicas para "sangrar" as árvores. 


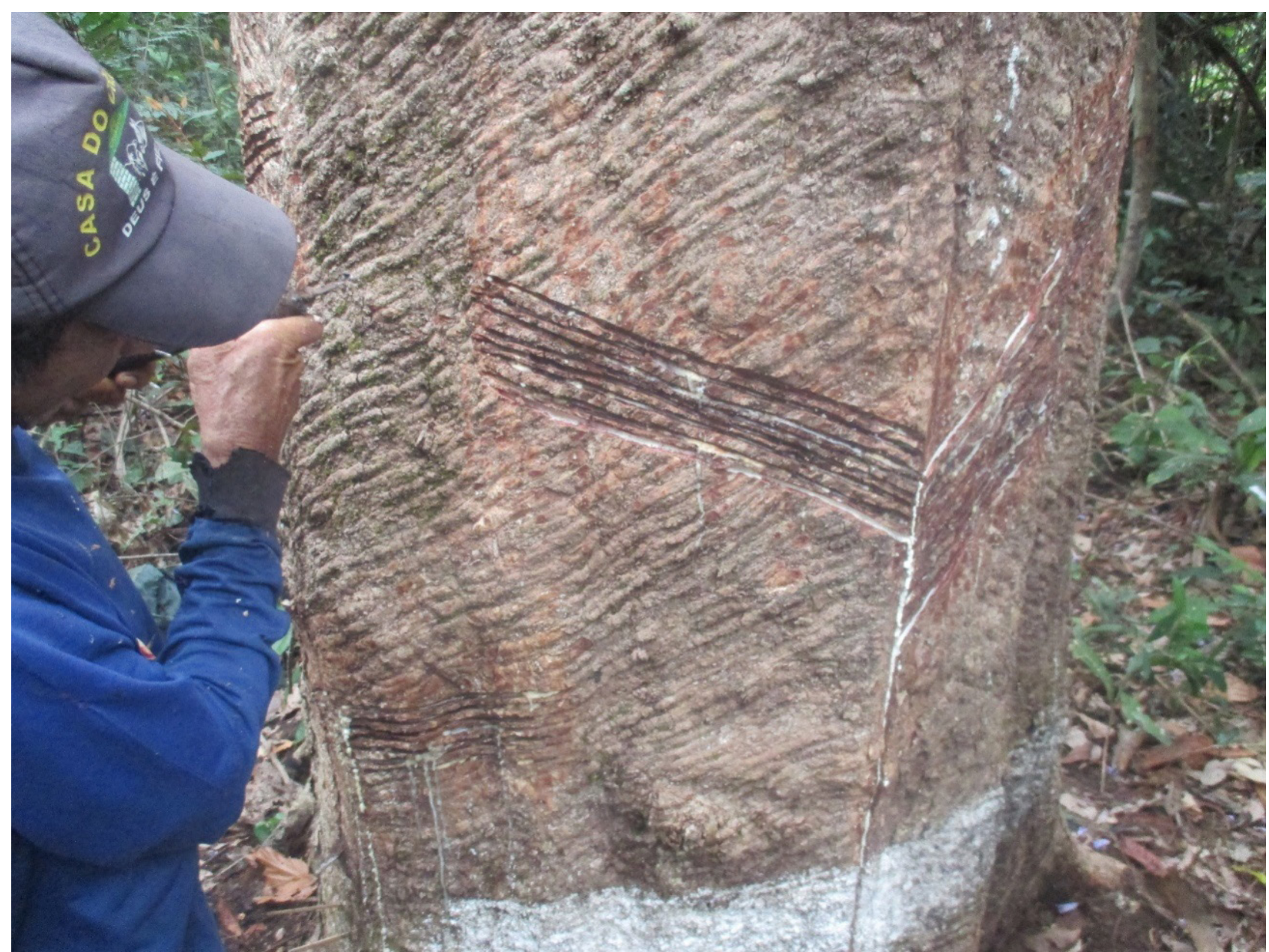

Figura 6: Seringueiro, Seu João, realizando o corte "rabo-de-peixe" no Seringal Veneza, Vila de Boim, Santarém, Pará. Foto: Autor.

Cabe ressaltar que no Brasil novas técnicas também estavam sendo criadas para otimizar a produção e evitar o declínio da economia gomífera. O médico Carlos de Cerqueira Pinto observou os malefícios dos gases tóxicos produzidos pelo processo de defumação da borracha e assim, em 1908, patenteou um método de coagulação do látex com a finalidade de preservação das propriedades elásticas da borracha e saúde do seringueiro, porém tal método não chegou a substituir a defumação com uso de frutos de palmeira (SANJAD, CASTRO, 2016).

As adequações sociotécnicas em seringais contemporâneos têm sido objeto de recente estudo na antropologia (DEUS, 2017). Do ponto de vista histórico, nota-se que a importação de novas tecnologias e técnicas veio de modo a suprimir os saberes locais, ainda que, conforme destacam Sanjad e Castro (2016), em 1911 Jacques Huber aponte que um "simples seringueiro de Portel" (Marajó, Pará) havia criado um método totalmente novo para vulcanização da borracha, atraindo assim a atenção científica e comercial durante exposição da borracha no Brasil. Entre as vinte e sete entrevistas realizadas na Vila de Boim em trabalho de campo junto aos seringueiros e seus remanescentes, destaca-se o modo de produção tradicional, tal qual Wickham (Fig. 1) houvera esquematizado. 
E: [para coleta] era a machadinha. Era machado que cortava. Rapava a seringueira.

T: E como coletava?

L: Fazia de caraná a cerca na seringueira né, com os trepzinho aguentava aquela calha. Aí caía e não estragava a madeira não. E hoje não, é na faca.

E: Não tem cuidado.

L: Naquele tempo eles cortavam com machadinha "tou" e aí descia o leite pra onde estiver na calha pra descer. E aí quando parava o tempo de compra de sernambi ou borracha o seringueiro ficava na dele, não estragava. Depois não, agora quando botou a faca... ela acaba aquela casca grossa e já vem uma fina, já mais fraca, porque eles cortam de lá e vem dourando a seringueira... desce muito, e a seringueira fica fraca. Cadê Belterra? Belterra era seringal, né? Hoje já não é mais seringal.

\section{E: É uma cidade.}

L: Porque estraga, a faca cortar a seringueira fica sem força e não dá mais leite que presta. Já é falsificado aquele leite (...). Naquele tempo não moço, cercava com o caraná uma seringueira, fazia calha, botava uma bica ali pra cair o leite aí ele vinha com o machadinho "tou". Faz aquela leira, "tou", "tou", caía naquela calha e ia... e hoje não, puxa da seringueira, capaz de matar ela logo. Mas isso é sabedoria do americano, tá? Porque na companhia de Belterra não tinha isso, depois quando aveio um sabidão, ensinou: pronto! Aí era tudo na faca. Meu pai trabalhou em Belterra quando começou lá. Plantava lá. Depois quando ela ficava mais adulta queriam cortar com a faca. E aqui pro interior não. O cara não cortava com faca, era com machadinho."

Entrevista realizada em 29/7/2019 com Dona Elísia (E), 73 anos e Seu Leôncio (L), 85 anos, moradores de Boim.

Diferentes discursos sobre eficácia, cuidado e expertise ao manejar as seringueiras se misturam à memória, o que pode revelar uma adequação sociotécnica e transferência de tecnologias em direção hierarquizada ou ainda, apenas um registro de 'saudosismo', conforme verificado pela narrativa genética - de um passado positivo e presente negativo (RÜSEN, 2004). Entretanto, o desenvolvimento de facas, diferentes tipos de corte e uso de óleos vegetais para a regeneração mais rápida da casca foram criados para maior eficácia dos seringais asiáticos (LOADMAN, 2006). Jacques Huber em 1911, à época diretor do Museu Paraense Emílio Goeldi, criou a faca-de-Huber e a patenteou, visando aumentar a produtividade e longevidade das árvores (SANJAD, CASTRO, 2016).

"Há, contudo, um silêncio constrangedor no texto de Huber, assim como no stand organizado por ele: o seringueiro e o seu trabalho estavam ausentes. (...) O modo de vida e as relações de trabalho do seringueiro, já longamente estudados como sendo conflituosos, de extrema dificuldade e próximos a uma forma de escravidão moderna, permaneciam invisíveis ao público da exposição, que, dessa maneira, seguia iludido pela imagem de uma república democrática que se pretendia civilizada, mas que era, em última instância, profundamente excludente. Convinha elidir, portanto, tudo o que lembrasse a desigualdade social brasileira." (SANJAD, CASTRO, 2016: 153-154).

João Pacheco de Oliveira abordou a existência de dois modelos de seringais no Brasil, o sistema de barracão, ou seringal do apogeu, e o seringal caboclo (MUNIZ, 2019, OLIVEIRA FILHO, 1979). O seringal caboclo seria associado a um primeiro momento e práticas tradicionais, já no seringal do apogeu a intensidade de trabalho aumenta, havendo relatos de situações análogas à escravidão. Roger Casement, irlandês que fora cônsul do Grão-Pará, foi internacionalmente reconhecido por seus trabalhos sobre a extração de látex no Congo e em Putumayo (Peru, atual Colômbia) no qual, 
denunciou uma série de crimes contra a humanidade, provenientes das relações de exploração em seringais (REILLY, 2017). Na Amazônia brasileira, ainda que o seringueiro fosse "socialmente livre", ele era escravo da dívida, insulamento, solidão e rotina que levava (MARTINELLO, 2004).

Cabe ressaltar que tal "solidão" silenciada em seringais apaga a presença indígena nas imediações dos barracões e nos traz questionamentos, tendo em vista que há ainda crescentes relatos sobre relações de gêneros em seringais (ALVES, PINTO, et al., 2018, BLANCO, BAMBIRRA, 2017, BRITO, 2018, LAGE, 2010). Assim sendo, é relevante situar o patrimônio da borracha em suas diversas camadas, materiais, imateriais, e também em sua dimensão sensível e tóxica. A dimensão do patrimônio tóxico da borracha por si só tem diversos aspectos; conforme supramencionado, a técnica de defumação da borracha é prejudicial à saúde, podendo em alguns casos levar à cegueira e outros problemas de saúde provenientes da inalação de polímeros. Aspectos de racialização, gênero e trabalho também são comumente observados como tóxicos em seringais, havendo situações até mesmo análogas à escravidão moderna. Por último, cabe destacar que o objetivo da borracha no norte do Brasil também tem intenção de expandir a ocupação neste território, ampliando as relações de colonialidade, reproduzidas através do que também pode ser definido como "seringalidade" (SOUZA, 2017).

\footnotetext{
“As condições impostas pela colonização aos povos indígenas da Amazônia e que abriram caminho para a implantação do seringalismo - de genocídio, escravidão, exploração e catequização - como modo racializado e assim inferiorizante de tratar o outro, seguem os métodos adotados desde o início da colonização a América, guardados as devidas proporções que foram submetidos os povos ameríndios, assim como os africanos sequestrados e trazidos para o Brasil como escravos. (...) sob condições subjetivas e materiais, isto é, sob discursos e sob o sistema de exploração econômica da borracha, com vistas a satisfazer no imediato aos mercados globais da indústria da Hevea brasiliensis, e, no mediato, em manter vigente o padrão colonial de poder, é que foi se instituindo um regime de escala local de colonialidade, ao qual, para efeito desta pesquisa, denominamos seringalismo, na sua fase de gênese estrutural, seringalidade, na sua fase atual. (SOUZA, 2017:148)". [grifos do autor]
}

O período da borracha é o período histórico da Amazônia mais estudado, seja sob os aspectos de migrações internas, boom da economia gomífera, políticas de incentivo para a produção da borracha ou, mais recentemente, sob olhar da antropologia acerca das relações comumente em seringais que tratam de racialidade, gênero, trabalho e seringalidade. Dessa forma, o seringalismo e a seringalidade destacam-se pela intensa exploração na Amazônia, do ambiente e pessoas.

\section{NA BELLE ÉPOQUE AMAZÔNIDA: BELLE ÉPOQUE PARA QUEM?}

"O que no léxico da História Cultural ficou configurado como belle époque indica um complexo processo de relações culturais, sociais e mentais, mas também materiais e políticas, desenvolvidas no interior de um corpus reconhecido historicamente como o da cultura burguesa e da sua afirmação no interior dos quadros hegemônicos do capitalismo industrial no final do século XIX. Em nome da identidade de um tempo cujos sujeitos sociais emergiram das novas condições econômicas e sociais dominantes no mundo do capital, a belle époque implica reconhecer linguagens, gostos, atitudes, estéticas, sociabilidades que, construídos em escalas diferenciadas nos espaços hegemônicos da cultura burguesa, reproduziramse, em escala planetária, também na condição das formas de ser e de agir em tempos que abrigavam o proclamado triunfo do Progresso e da sua homologia, a Civilização. (...) A belle époque, entendida como manifestação da Idade de Ouro da cultura urbana da burguesia 
contemporânea, e cujos quadros tradicionais, como visto, remetem para a Paris do final do século XIX e começo do XX, sempre foi um domínio visitado pela narrativa social brasileira. As próprias transformações urbanas de cidades como Belém e Rio de Janeiro no mesmo período foram tratadas como dimensões especulares da belle époque matricial, parisiense, nas latitudes sociais e mentais do trópico brasileiro." (COELHO, 2011).

Forjada na labuta dos seringais, a economia gomífera subsidiou a classe burguesa em ascensão, higienizando socialmente e reconstruindo as maiores cidades amazônicas para consumir as artes de aspiração parisiense. Nos "chás-dansantes", cinemas e teatros que a elite belenense dos anos 19101920 frequentava, ainda que a maior parte da população estivesse submetida a problemas estruturais e suas atribulações, a "alta sociedade" desfilava suas roupas ostensivas em tempos de crise econômica (MARTINS JÚNIOR, 2010). Em 1910 a imposição da vida moderna também é proeminente em Manaus, onde utilizar palhas para cobrir as casas passa a ser considerado "insalubre e feio". O sanitarismo vai suprimindo a "rudeza" e habitar casas com separação de cômodos, ainda que predominantemente taperas ou ocas, passa a ser a norma local. Equitativamente, a vestimenta torna-se a representação das forças da modernidade sobre o nu ameríndio rumo ao aceite da ocidentalidade (SANTOS JÚNIOR, 2013). É na comparação com o Oriente que os europeus criam a noção de Ocidente, do mesmo modo que ao trazer o Oriente à modernidade, novos mundos eram inventados (SAID, 1990).

Em seringais e barracões destaca-se o odor característico da borracha e de seu processamento; em relatos históricos sobre o boom da borracha na Amazônia, os odores fétidos também são mencionados. O fato é que, além de um peculiar sentido, a química da borracha também pode ser prejudicial à saúde, principalmente com o método de defumação e inalação de polímeros, extremamente nocivo. Com efeito, tal toxicidade estava presente durante o primeiro ciclo da borracha (Figura 7).

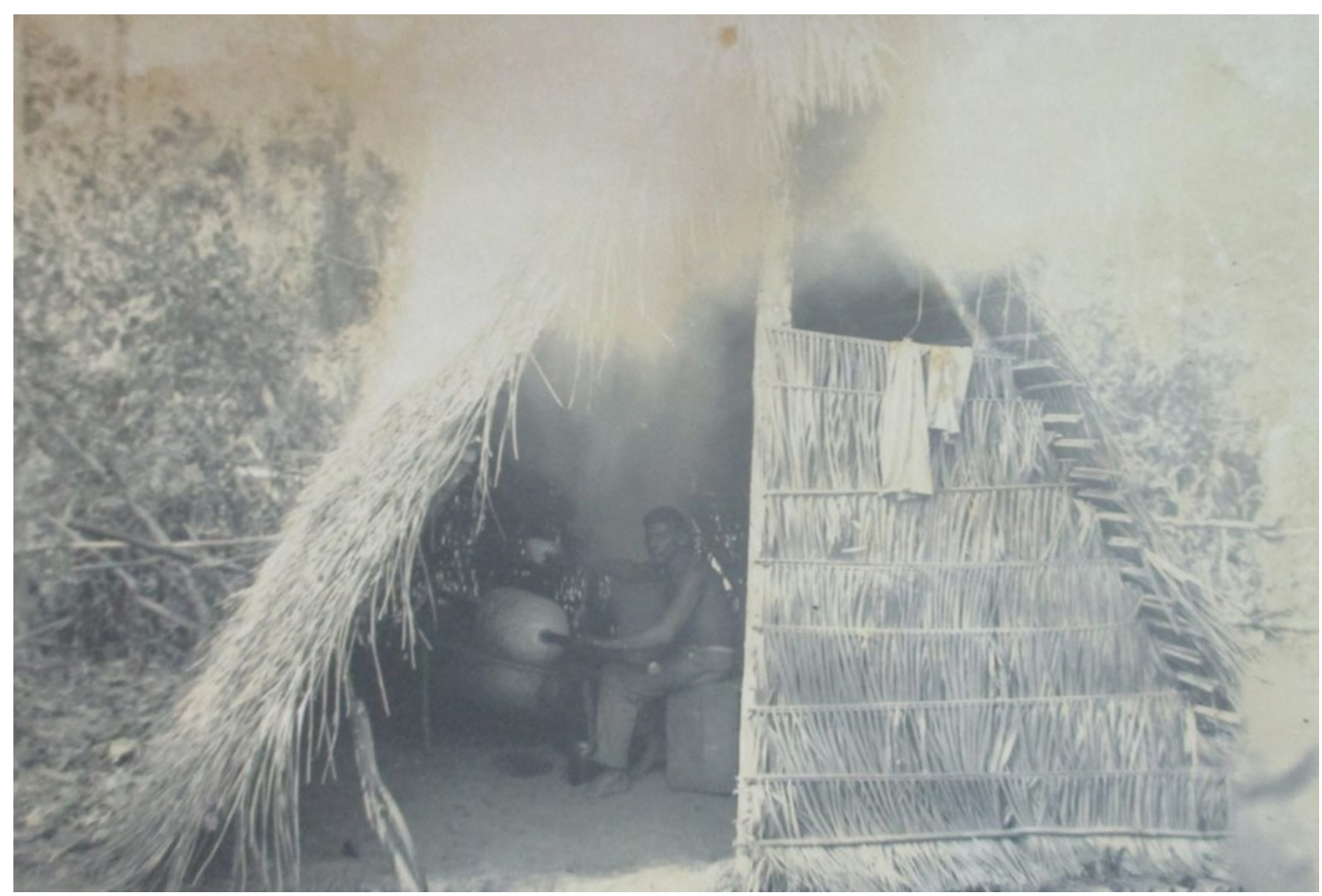

Figura 7: Modo de fazer bolota de borracha durante o primeiro ciclo econômico: o método de defumação (ULE, 1908). 
A exemplo de tal toxicidade, o pagamento de adicional de insalubridade ainda entre as décadas de 1950-1980 foi uma pauta dos borracheiros como ação paliativa frente à sensação térmica e odores resultantes da vulcanização da borracha. Segundo os trabalhadores, "tinha que ser macho" para suportar o barulho, calor, dispersão de pó e de produtos químicos no ar e mau cheiro (REZENDE, 2013). Cabe ressaltar que os saberes locais na Amazônia apontam o uso de ingredientes locais para acelerar o processo de "coalhar o leite" da seringueira (MUNIZ, 2019), ao qual não foi creditada cientificidade ou eficácia, sendo suprimido pelas patentes para vulcanização (HILLS, 1971) e colonialidade do saber (LANDER, 2005).

Há, portanto, um emaranhado de saberes, materiais e mundos que fluem entre os saberes caboclos, indígenas, negros, ribeirinhos, judeus e outros mais no contexto da borracha na Amazônia. Ademais, as florestas e não-humanos também interagem com os seringueiros que suportam a labuta e têm a sua agência invisibilizada enquanto escoa sua produção para abastecer o modo de vida burguês em ascensão e a consolidação do Sistema-Mundo (WALLERSTEIN, 2005).

\section{O SONHO AMERICANO QUE NÃO DEU CERTO: FORD VERSUS ACTANTES}

Após o colapso do boom da borracha no Brasil (1850-1920), Henry Ford tentou criar sua metrópole nos trópicos através da implementação de uma plantação de seringueira em uma cidade americana no Baixo Amazonas. Entretanto, a ação de fungos sobre a plantação logo começou a frear seus planos e, junto às doenças tropicais, Fordlândia (1928-1945) foi abandonada (Fig. 8). Hoje, Fordlândia é citada como uma "cidade fantasma" ${ }^{1}$.

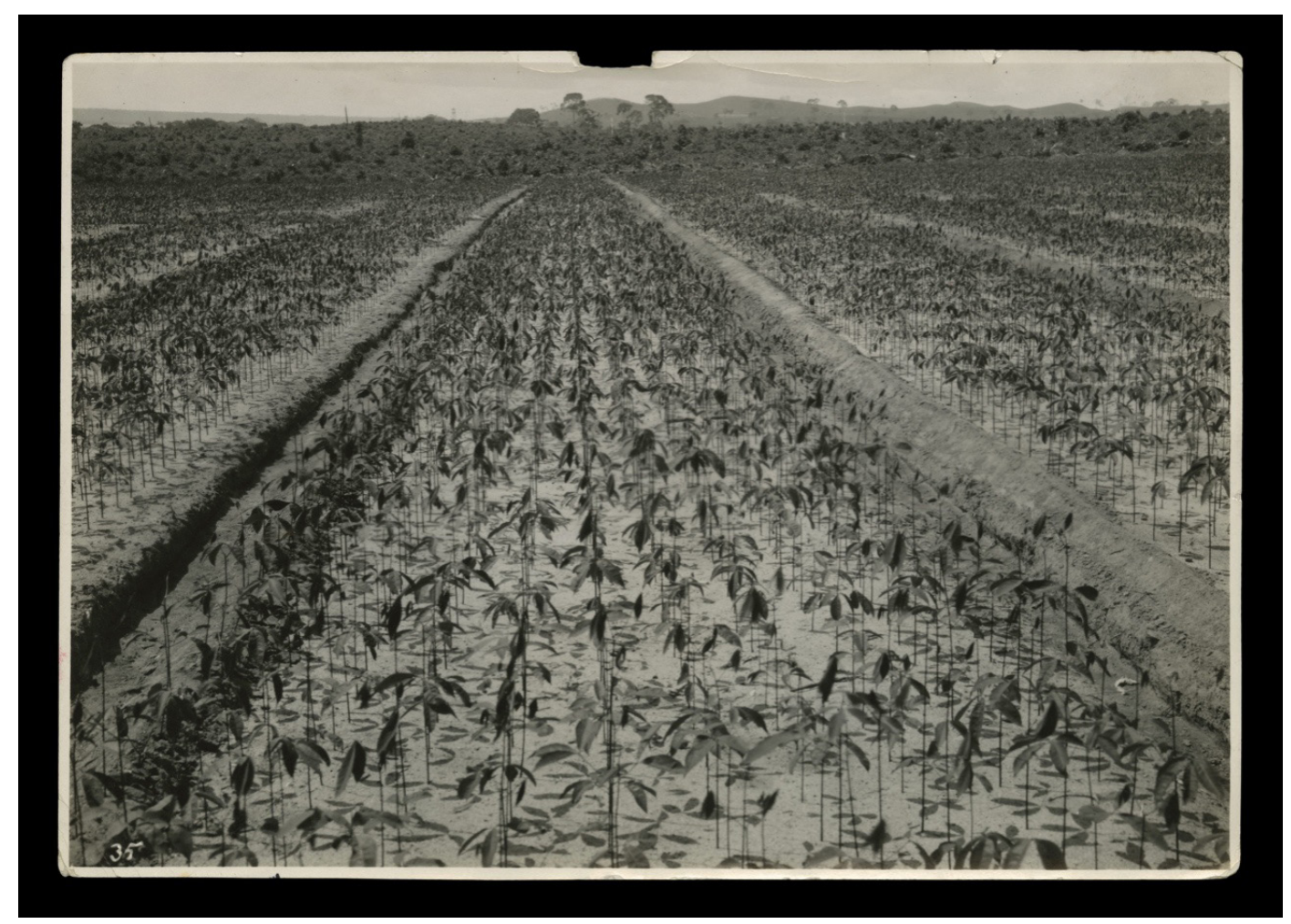

Figura 8 Plantação de Hevea brasiliensis em Fordlândia. Destaca-se a distância diminuta entre as mudas plantadas, o que possivelmente inviabilizou o crescimento das árvores e contribuiu para a proliferação do fungo (mal-das-folhas). Fonte: The Henry Ford. 
Desse modo, discutir o período da borracha (em ambos os ciclos) deve açambarcar todas essas assinaturas de actantes, como diria Latour, sem erroneamente essencializar ou purificar em categorias de "natureza" e "sociedade" (LATOUR, 1994). O termo actante designa um ator não humano ou entidade não individual e pode ser literalmente qualquer coisa com ação no complexo ator-rede (LATOUR, 2017). Nesse contexto no qual o fungo emaranha-se às árvores e humanos ao frear o sonho de uma metrópole estadunidense na Amazônia, o debate sobre modernidade, humanidade, agências e actantes, no presente, emerge sob os olhares da arqueologia do contemporâneo ou ainda, outras arqueologias: da modernidade, do capitalismo, industrial, da segunda guerra mundial, do período da borracha, pública, social, inclusiva, da colonialidade/seringalidade, do presente, etc.

Os mais entusiastas diriam que não seria possível imaginar o "mundo moderno" sem borracha, ou ainda, nunca fomos modernos. Ainda assim, os materiais produzidos a partir da borracha amplificaram as atividades humanas, possibilitando por meio da assepsia e globalização, a expansão de interações entre corpo e meio ambiente. Entre tais materiais se destacam as botas de borracha para neve, pneus, luvas e itens médicos/industriais. As luvas de borracha foram desenvolvidas de paramentação médica; pneus de borracha expandiram zonas de atividade humana por carros/ aviões em todo o mundo; a borracha também foi usada para fazer botas de neve, o que melhorou a capacidade humana durante o inverno, e ainda os itens industriais produzidos de borracha, que ajudaram na consolidação da segunda revolução industrial.

Ainda segundo Latour (1994), para existir algo "moderno" é necessário haver uma ruptura entre os "antigos" e "modernos" havendo uma assimetria disruptiva e, dessa forma, para o autor, jamais fomos modernos. Já no sentido relacional de humanos e outros organismos, ferramentas e muito mais, "humano" adquire um sentido de produto de relacionalidades, temporalidades e materialidades, conceituando uma multiespécie, ou ainda, questionando se nunca fomos humanos (GANE, HARAWAY, 2010). Nesse desafio de construir uma antropologia mais que humana, emerge a noção de "biologias substantivas" onde, simbiose e mutualismos multiespécies também dizem respeito à antropologia (TSING, 2019). Tal posicionamento por uma biologia substantiva aponta uma série de relações onde organismos emergem de relações, destacando desse modo que "jamais fomos indivíduos" (GILBERT, SAPP, et al., 2012).

Os fungos como tais actantes que frearam o sonho americano de uma metrópole na Amazônia apontam para mais uma camada dos emaranhamentos da borracha: a abordagem multiespécie. Microcyclysulei é o fungo conhecido como mal-das-folhas e responsável por frustrar os plantios adensados de seringueiras por parte da Ford Motor Company. Entretanto, a dispersão deste fungo está restrita ao continente americano, sendo esse também um dos fatores que contribuíram para o sucesso da implementação de plantios nas colônias britânicas na Ásia.

Nesse contexto de relações em seringais, em Fordlândia desponta-se o debate acerca do patrimônio industrial e material do período da borracha, tendo em vista que há um processo de tombamento em andamento, iniciado em $1990^{2}$. Destarte, Fordlândia poderia ser considerada como um patrimônio industrial da borracha, entretanto, nesse complexo patrimonial, a fábrica é apenas

Número do procedimento: 1311-T-99/1990. 
a ponta do iceberg, pois eram nas matas que ocorria a labuta para "sangrar" a seringa e produzir o tão cobiçado "outro negro". Nesse sentido, destaco que há um amalgamado de saberes associados (MUNIZ, 2019) e materiais históricos associados (MUNIZ, 2020) com o processo de extração e produção da borracha e saberes associados.

\section{VÃO-SE AS SEMENTES, FICAM AS ÁRVORES: ARQUEOLOGIA CONTEMPORÂNEA DE UM PRESENTE EMERGENTE}

A "arqueologia do passado contemporâneo" é um campo que argumenta por maior integração do campo expandindo a arqueologia histórica e preocupação social, política, econômica, ecológica e também dos futuros e passados emergentes (HARRISON, CABRAL, 2019)contemporâneos e sócio materiais e, consequentemente, com questões - tanto contemporâneas quanto futuras - de interesse ecológico, social, político e econômico. Partindo do quadro de um novo projeto de pesquisa interdisciplinar, colaborativo e internacional - Futuros do Patrimônio - que procura compreender os processos material-discursivos do patrimônio e de outros campos similares como formas distintivas de práticas de construção de futuros (future-assembling. Dessa forma, a arqueologia do contemporâneo é um campo que tem discutido tanto os objetos do passado no presente, ou o próprio estudo do contemporâneo, como um dos campos da arqueologia - entendida aqui como ciência dos estudos da materialidade. A valer, outro modo de pensar a arqueologia que trabalha com comunidades locais, investigando a vida cotidiana, seus emaranhamentos, coisas e paisagens, vem advogando que a etnoarqueologia deva ser remodelada como a arqueologia do presente (GONZÁLEZ-RUIBAL, 2006).

Uma arqueologia sem limites temporais, multitemporal, participativa e pública, política, criativa, com sua própria retórica, que reivindica a materialidade, em pé de igualdade com outras ciências, de característica global e essencialmente teórica, são alguns dos elementos críticos para tornar a disciplina mais relevante cientificamente e socialmente (GONZÁLEZ-RUIBAL, 2012). Da mesma forma que existem diferentes engajamentos da arqueologia com o presente, existem diversos passados que diversas arqueologias produzem, assim como diversos futuros possíveis (HARRISON, CABRAL, 2019)contemporâneos e sócio materiais e, consequentemente, com questões - tanto contemporâneas quanto futuras - de interesse ecológico, social, político e econômico. Partindo do quadro de um novo projeto de pesquisa interdisciplinar, colaborativo e internacional - Futuros do Patrimônio - que procura compreender os processos material-discursivos do patrimônio e de outros campos similares como formas distintivas de práticas de construção de futuros (future-assembling. De tal maneira, o patrimônio pode ser entendido como práticas que criam futuros (HARRISON, DESILVEY, et al., 2020).

O estudo de novas materialidades, imaterialidades e diversos trabalhos vêm sendo conduzidos sobre as relações de/em/para/por comunidades locais e guinadas rumo a uma postura descolonizante da arqueologia (ATALAY, 2008, SILLIMAN, 2008). Há, portanto, uma necessidade de fazer uma arqueologia da colonialidade/modernidade, ampliando o engajamento público da 
disciplina. Nesse sentido, o presente artigo argumenta por uma arqueologia mais elástica, tanto ao olhar para seu próprio campo de estudo, seguindo mais essa corrente interdisciplinar da arqueologia contemporânea, como também na própria relação com as comunidades e saberes, com a finalidade de incorporar também a história oral e outras ferramentas que viabilizam melhor compreensão das materialidades junto às comunidades locais.

A borracha está entre as quatro sementes que tiveram um efeito profundo nas relações socioeconômicas em todo o planeta, criando elites abrangendo a exploração de madeira, uva para vinho, borracha e tabaco (HOBHOUSE, 2004). Nesse contexto, abordar o patrimônio industrial do período da borracha para além da materialidade fabril e seu maquinário direciona o foco para as pessoas e suas relações. Entender o contexto do colonialismo botânico, a aquisição de sementes de borracha na Amazônia e o abandono de vilas e cidades, faz parte de entender tais relações que a colonialidade traçou ao criar o Ocidente e modernidade. Aproximar-se do campo de estudo da memória, história oral e patrimônio, é também lançar novas perspectivas sobre materialidades, emaranhamentos e até mesmo contribuir para maior divulgação da arqueologia como uma ciência popular.

\section{CONSIDERAÇÕES FINAIS}

Ao concluir, este artigo aponta para a necessidade de maiores estudos dos períodos históricos na Amazônia, nos quais os ciclos do cacau e borracha, entre outras drogas do sertão, obtiveram relevância primordial para as transformações sociais ocorridas na região, sendo o período da borracha, em ambos seus ciclos (1850-1920 e 1942-1945), o mais estudado pela historiografia. Desse modo, tanto a abordagem da arqueologia histórica quanto a arqueologia desse passado contemporâneo, presente emergente ou ainda patrimônios futuros, visam compreender os aspectos materiais/ imateriais remanescentes e em transformação. Portanto, a arqueologia da economia gomífera pode ajudar a expandir uma série de análises sobre história e contemporâneo na Amazônia. Desde tal abordagem, a arqueologia do período da borracha pode se relacionar às diversas subáreas da arqueologia e outras disciplinas como a história, antropologia, biologia, ecologia, química e muitas outras.

O patrimônio material associado ao período da borracha, para além da Casa de Chico Mendes (Xapuri, Acre), ainda não é tombado. Conforme aqui mencionado, Fordlândia possui um procedimento para tombamento em andamento desde 1990, no qual o patrimônio industrial da empresa Ford Motor Company é o objeto central. Entretanto, o patrimônio imaterial da borracha ainda carece de análise mais profunda, tal como a própria modificação da floresta, visando abastecer a indústria: poder-se-ia considerar tais emaranhamentos como uma parte de tal complexo do patrimônio industrial? A materialidade da borracha, como um elástico, responderia tal questionamento, uma vez que, foi através das relações em tais florestas e propriedades de materiais feitos a partir de $H$. brasiliensis que a humanidade expandiu suas interações estreitando distâncias e relações, ou mesmo consolidando a revolução industrial e, por conseguinte, a "modernidade". 
Na hipótese de que somos modernos ou humanos, foram exatamente esse emaranhamento de coisas, plantas, fungos, humanos e não-humanos que viabilizaram papel primordial da borracha, gerando tecnologias, poder e desigualdades. Destarte, nos estudos sobre materialidade do período da borracha, destacam-se as relações humanas, coisas, florestas, fungos, não-humanos e multiespécies. Antropoceno, ou muitos outros nomes para este período, também se insere no contexto desta pesquisa. Nesse sentido, aqui o complexo patrimonial, material e imaterial, visa compreender o patrimônio tóxico relativo, demais relações em seringais e extroversão de tais arqueologias sobre a borracha de forma elástica, junto/com/para/por comunidades locais e relações mais estreitas de arqueologia social, inclusiva, pública, política e voltada para os estudos de patrimônios futuros com abordagem crítica.

Cabe ainda destacar que o presente trabalho visa expandir visão sobre a Arqueologia Amazônica para além daquela essencialmente voltada para os estudos de história profunda e tradições arqueológicas. Situando, portanto, o olhar para a Amazônia mais adiante da melancolia ou abordagem de "perda" cultural/natural. Dessa forma, a dimensão material da borracha chancela o protagonismo amazônico na construção da modernidade. Nesse sentido, tópicos como estudos de company-towns; relações humanos, não-humanos, cultura material/imaterial com as drogas do sertão e; construção da própria noção de modernidade foram aqui abordados de maneira introdutória e serão expandidos nas próximas publicações.

\section{AGRADECIMENTOS}

O presente trabalho foi realizado com apoio da Coordenação de Aperfeiçoamento de Pessoal de Nível Superior (CAPES), Código de Financiamento 001. Agradeço aos professores orientadores e parceiros desta pesquisa: Diogo Costa (UFPA), Floriano Pastore Jr. (UnB) e Cornelius Holtorf (Lnu) e às comunidades de seringueiros da Amazônia, em especial da Vila de Boim, Resex Tapajós-Arapiuns e Flona do Tapajós e demais comunidades locais. 


\section{REFERÊNCIAS BIBLIOGRÁFICAS}

ALVES, E. da S., PINTO, A. dos S., CAETANO, R. F. "Memórias de Mulheres Seringueiras na Reserva Extrativista Rio Ouro Preto/RO: Linguagem, Cultura e Identidade", Amazônica - Revista de Antropologia, v. 10, n. 2, p. 738-761, 2018. .

ATALAY, S., "Multivocality and Indigenous Archaeologies Beyond Nationalist: Global Applicability of Indigenous Archaeologies". Evaluating Multiple Narratives: Beyond Nationalist, Colonialist, Imperialist Archaeologies, [S.I.], Springer, 2008. p. 29-44.

BEZERRA, M. "“ As moedas dos índios ": um estudo de caso sobre os significados do patrimônio arqueológico para os moradores da Vila de Joanes, ilha de Marajó, Brasil "The coins of Indians ": a case study about the meanings of Archaeological heritage to the local co", v. 110, p. 57-70, 2011. .

BEZERRA, M. "Signifying heritage in amazon: A public archaeology project at vila de Joanes, Marajó Island, Brazil", Chungara, v. 44, n. 3, p. 533-542, 2012. DOI: 10.4067/S071773562012000300015. .

BLANCO, S. V. N., BAMBIRRA, V. L. de M. "A figura feminina no seringal: vozes silenciadas", Revista communitas, v. 1, n. 1, p. 144-160, 2017. .

BRITO, A. L. "“Eu trabalhei também": as trabalhadoras nos seringais do Amazonas (1940-1950)", História \& Parcerias, n. Anais do Encontro Internacional e XVIII Encontro de História da Anpuh-Rio, 2018. .

BROCKWAY, L. H. Science and Colonial Expansion: The Role of the British Royal Botanic Gardens. Kew Bulletin. [S.I: s.n.]. , 1982

CHAMPNEY, J. W. Travels in the North of Brazil. [S.I: s.n.], 1860. Disponível em: http://www.bndigital. bn.gov.br//acervo-digital.

COELHO, G. M. "Na Belém da belle époque da borracha (1890-1910): dirigindo os olhares", Escritos V, p. 141-168, 2011. .

COHEN, E. E. Vila de Boim (1690-1986) sua história, seu povo. Obras lite ed. Santarém, Tiagão, 1985.

COSTA, D. M. "Arqueologia Histórica Amazônida", Revista de Arqueologia, v. 30, n. 1, p. 154-174, 2017. DOI: 10.24885/sab.v30i1.506.

DAOU, A. M. A belle époque amazônica. 3. ed. [S.I.], Zahar, 2004.

DEUS, E. Di. A dança das facas: Trabalho e técnica em seringais paulistas. 2017. Universidade de Brasília, 2017.

GANE, N., HARAWAY, D. "Se nós nunca fomos humanos, o que fazer?", Ponto Urbe, v. 6, n. 6, p. 1-22, 2010. DOI: 10.4000/pontourbe.1635. Disponível em: http://pontourbe.revues. $\operatorname{org} / 1635$.

GILBERT, S. F., SAPP, J., TAUBER, A. I. "A symbiotic view of life: We have never been individuals", Quarterly Review of Biology, v. 87, n. 4, p. 325-341, 2012. DOI: 10.1086/668166.

GOMES, D. M. C. "História da Arqueologia Amazônica no Museu Nacional: diferentes narrativas", Revista de Arqueologia, v. 33, n. 1, p. 03-27, 2020. DOI: 10.24885/sab.v33i1.694. . 
GONZÁLEZ-RUIBAL, A. “Hacia otra arqueología: diez propuestas", Complutum, v. 23, n. 2, p. 103116, 2012. DOI: 10.5209/rev-CMPL.2012.v23.n2.40878. .

GONZÁLEZ-RUIBAL, A. "The Past is Tomorrow. Towards an Archaeology of the Vanishing Present", Norwegian Archaeological Review, v. 39, n. 2, p. 110-125, 2006. DOI: 10.1080/00293650601030073. .

HARRISON, R., CABRAL, M. P. "Arqueologias de futuros e presentes emergentes", Vestígios - Revista Latino-Americana de Arqueologia Histórica, v. 12, n. 2, p. 83-104, 2019. DOI: 10.31239/ vtg.v12i2.12200. .

HARRISON, R., DESILVEY, C., HOLTORF, C., et al.Heritage futures: Comparative approaches to natural and cultural heritage practices. [S.I: s.n.], 2020.

HILLS, D. A. Heat transfer and vulcanisation of rubber. [S.I.], Elsevier Publishing Company, 1971.

HOBHOUSE, H. Seeds of wealth: Four plants that made men rich. [S.I.], Counterpoint Press, 2004.

JACKSON, J. O ladrão no fim do mundo: como um inglês roubou 70 mil sementes de seringueira e acabou com o monopólio do Brasil sobre a borracha. São Paulo, [s.n.], 2011.

LAGE, M. M. L. Mulher e seringal: um olhar sobre as mulheres nos seringais do Amazonas (18801920). 2010. 166 f. Universidade Federal do Amazonas, 2010.

LANDER, E. A Colonialidade do Saber - Eurocentrismo e Ciências Sociais - Perspectivas Latinoamericanas. [S.I: s.n.], 2005.

LATOUR, B. “Jamais fomos modernos", Coleção TRANS, p. 151, 1994. .

LATOUR, B. "On actor-network theory. A few clarifications, plus more than a few complications", Logos (Russian Federation), v. 27, n. 1, p. 173-200, 2017. DOI: 10.22394/0869-53772017-1-173-197. .

LEVIS, C., FLORES, B. M., MOREIRA, P. A., et al."How people domesticated Amazonian forests", Frontiers in Ecology and Evolution, v. 5, n. JAN, 2018. DOI: 10.3389/fevo.2017.00171. .

LOADMAN, J. Portrait of the Global Rubber Industry: Driving the Wheel of the World Economy. [S.I.], International Rubber Research \& Development Board, 2006.

MAEZUMI, S. Y., ROBINSON, M., SOUZA, J. de, et al. "New insights from pre-Columbian land use and fire management in Amazonian dark earth forests", Frontiers in Ecology and Evolution, v. 6, n. AUG, 2018. DOI: 10.3389/fevo.2018.00111. .

MARTINELLO, P. A “batalha da borracha” na segunda guerra Mundial. Rio Branco, EUFAC, 2004.

MARTINS JÚNIOR, R. J. M. Visto, logo existo : moda , sociabilidade feminina e consumo em Belém no limiar do século XX. 2010. 1-152 f. 2010.

MUNIZ, T. S. A. "Ensaio sobre arqueologia do período da borracha no Baixo Amazonas: materialidade, ontologia e patrimônio", Oficina Do Historiador, v. 13, n. 1, p. 1-17, 2020. .

MUNIZ, T. S. A. “Os agentes do deus elástico no Baixo Amazonas: apontamentos sobre materialidade e patrimônio do período da borracha", ACENO - Revista de Antropologia do CentroOeste, v. 6, n. 11, 2019. .

OLIVEIRA FILHO, J. P., "O caboclo e o brabo: notas sobre duas moda- lidades de força de trabalho na 
expansão da fronteira amazônica do século XIX". Encontros com a civilização brasileira, Rio de Janeiro, Civilização Brasileira, 1979. p. 101-140.

REILLY, F. "Roger Casement - voice of the voiceless", History Ireland Magazine, v. 25, n. 1, 2017. Disponível em: https://www.historyireland.com/volume-25/roger-casement-voicevoiceless/.

REZENDE, V. "“Tinha que ser macho": as condições de trabalho e as disputas em torno do adicional de insalubridade no setor coureiro-calçadista de Franca-SP (1950-1980)". 2013. Anais [...] [S.I: s.n.], 2013.

RÜSEN, J., "Historical consciousness: Narrative structure, moral function and ontogenetic development". Theorizing historical consciousness, Toronto, University of Toronto Press, 2004. p. 63-85.

SAID, E. W. Orientalismo: o oriente como invenção do ocidente. [S.I: s.n.], 1990.

SANJAD, N., CASTRO, A. R. M. "Comércio, política e ciência nas exposições internacionais", Varia Historia, Belo Horizonte, v. 32, n. 58, p. 141-173, 2016. DOI: 10.1590/010487752016000100007. Disponível em: http://dx.doi.org/10.1590/0104.

SANTOS JÚNIOR, P. M. dos. "Manaus da Bélle Époque: tensões entre culturas, ideais e espaços sociais". 2013. Anais [...] [S.I: s.n.], 2013.

SHEPHERD, N., "The conquest of time". Arqueología y decolonialidad, Ediciones ed. Buenos Aires, University, Duke, 2016. .

SILLIMAN, S. W., "Collaborative Indigenous Archaeology Troweling at the Edges, Eyeing the Center". Collaborating at the Trowel's Edge: Teaching and Learning in Indigenous Archaeology, [S.I: s.n.], 2008. .

SOUZA, J. J. V. de. Seringalidade: o estado da colonialidade na Amazônia e os condenados da floresta. Manaus, Valer, 2017.

TSING, A. L. “Viver nas ruínas: paisagens multiespécies no Antropoceno”, p. 284, 2019. .

ULE, E. Coleção Fotográfica. Arquivo Guilherme de la Penha. . Belém, [s.n.], 1908.

WALLERSTEIN, I. World-systems analysis: an introduction. [S.I.], Duke University Press, 2005.

WEINSTEIN, B. A borracha na Amazônia: expansão e decadência (1850-1920). São Paulo, Hucitec/ Edusp, 1993.

WICKHAM, H. A. Letter from Wickham to Hooker. Miscellaneous Reports - MR/117 India Office Caoutchouc Vol 1 c. 1873-1904. Introduction of Hevea brasiliensis (f.1-144). . London, [s.n.], 1873.

WILLIS, J. C. The Ceylon Rubber Exhibition 1906. Kew Gardens Archives. Miscellaneous Reports, p. 1880-1908. . [S.I: s.n.], 1906. 